\title{
Pillars of Life: Is There a Relationship between Lifestyle Factors and the Surface Characteristics of Dragonfly Wings?
}

Samuel Cheeseman, ${ }^{\dagger, \nabla}$ Stephanie Owen, ${ }^{\dagger, \nabla}$ Vi Khanh Truong, ${ }^{\dagger}$ Denny Meyer, ${ }^{\dagger}$ Soon Hock Ng, ${ }^{\dagger}$

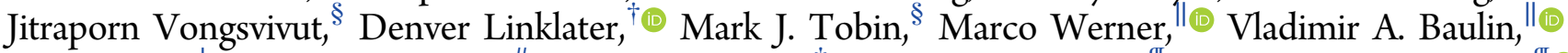
Pere Luque, ${ }^{\perp}$ Richard Marchant, ${ }^{\#}$ Saulius Juodkazis, ${ }^{\dagger}$ Russell J. Crawford, ${ }^{\mathrm{TI}}$ and Elena P. Ivanova*, ${ }^{\text {II }}$

${ }^{\dagger}$ School of Science, Faculty of Science, Engineering and Technology, and ${ }^{\ddagger}$ School of Health Sciences, Faculty of Health, Arts and Design, Swinburne University of Technology, P.O. Box 218, Hawthorn, Victoria 3122, Australia

${ }^{\S}$ Infrared Microspectroscopy Beamline, Australian Synchrotron, 800 Blackburn Road, Clayton, Victoria 3168, Australia

"Departament d'Enginyeria Quimica, Universitat Rovira i Virgili, 26 Av. dels Paisos Catalans, 43007 Tarragona, Spain

${ }^{\perp}$ Museu de les Terres de l'Ebre, Gran Capità, 34, 43870 Amposta, Spain

${ }^{\#}$ Museum Victoria, P.O. Box 666, Melbourne, Victoria 3001, Australia

${ }^{\text {IIS }}$ chool of Science, College of Science, Engineering and Health, RMIT University, GPO Box 2476, Melbourne, Victoria 3001, Australia

\section{Supporting Information}

ABSTRACT: Dragonfly wings are of great interest to researchers investigating biomimetic designs for antiwetting and antibacterial surfaces. The waxy epicuticular layer on the membrane of dragonfly wings possesses a unique surface nanoarchitecture that consists of irregular arrays of nanoscale pillars. This architecture confers superhydrophobic, selfcleaning, antiwetting, and antibiofouling behaviors. There is some evidence available that suggests that lifestyle factors may have influenced the evolution of the wing nanostructures and, therefore, the resulting properties of the wings; however, it appears that no systematic studies have been performed that have compared the wing surface features across a range of dragonfly species. Here, we provided a comparison of relevant wing surface characteristics, including chemical composition, wettability, and nanoarchitecture, of seven species of dragonfly from three families including Libellulidae, Aeshnidae, and Gomphidae. The characteristic nanopillar arrays were found to be present, and the chemical composition and the resultant wing surface superhydrophobicity were found to be well-conserved across all of the species studied. However, subtle differences were observed between the height, width, and density of nanofeatures and water droplet bouncing behavior on the wing surfaces. The results of this research will contribute to an understanding of the physical and chemical surface features that are optimal for the design of antiwetting and antibacterial surfaces.

\section{INTRODUCTION}

The epicuticle of dragonfly wings possesses nanoscale pillar arrays that confer a number of desirable properties, such as superhydrophobicity, self-cleaning ability, and antibacterial activity. ${ }^{1-4}$ The surfaces of these high-aspect ratio nanopillars are composed primarily of aliphatic hydrocarbons and palmitic acid and tend to cluster together in an irregular pattern. ${ }^{1,3,5}$ The unique combination of surface chemistry and nanoarchitecture makes the wing surface superhydrophobic, resulting in "selfcleaning" properties, where contaminants are removed as water droplets roll off the surface. ${ }^{4,6}$ This was initially thought to have evolved as an antifouling strategy, preventing contamination of the wings with debris and microorganisms. ${ }^{7}$ Recently, it was discovered that these unique nanostructures also display bactericidal activity against a broad range of cells via a mechanism that causes rupturing of the cell membrane., Synthetic biomimetic surfaces that imitate this nanoarchitecture have been shown to demonstrate similar superhydrophobicity, self-cleaning, and bactericidal properties and hence show promise for medical and industrial applications. ${ }^{8-13}$

The wings of insects have been of great interest across many disciplines as a flexible, strong, and lightweight material with unique aerodynamic and antiwetting properties. ${ }^{14-17}$ Oh et al. conducted a comparison of the wings of several cicada species across different habitats. ${ }^{18}$ The epicuticle of cicada wings contains nanopillars that are shorter and exist in a more regular

Received: April 20, 2018

Accepted: May 7, 2018

Published: June 5, 2018 
Table 1. Characteristics of Dragonfly Species

\begin{tabular}{|c|c|c|c|c|c|c|}
\hline family & species & $\begin{array}{l}\text { body length } \\
\text { (mm) }\end{array}$ & $\begin{array}{c}\text { geographic } \\
\text { location }\end{array}$ & migratory & foraging & preferred habitat \\
\hline \multirow[t]{4}{*}{ Libellulidae } & Austrothemis nigrescens & unknown & Australia & no & percher & lakes, swamps, permanent ponds ${ }^{24}$ \\
\hline & Orthetrum chrysostigma & $42-45.5^{25}$ & Europe & no $^{26}$ & percher $^{25}$ & standing or slow water ${ }^{26}$ \\
\hline & Trithemis annulata & $35-37^{25}$ & Europe & yes $^{27}$ & percher $^{25}$ & still and running water ${ }^{27}$ \\
\hline & Sympetrum fonscolombii & $33-40^{28}$ & Europe & yes $^{28}$ & hawker $^{28}$ & still waters $^{28}$ \\
\hline \multirow[t]{2}{*}{ Aeshnidae } & Anax parthenope & $62-75^{28}$ & Europe & yes $^{29}$ & hawker $^{28}$ & still ponds and lakes, can tolerate slow running water ${ }^{28}$ \\
\hline & Anax imperator & $66-84^{28}$ & Europe & yes $^{30}$ & hawker $^{30}$ & standing or slow open bodies of water ${ }^{30}$ \\
\hline Gomphidae & Onychogomphus forcipatus & $36^{31}$ & Europe & no $^{32}$ & percher $^{31}$ & rivers and streams ${ }^{32}$ \\
\hline
\end{tabular}

spatial arrangement on the surface than those of dragonfly wings, but similarly display bactericidal activity against a selective range of bacterial cells. ${ }^{2,19,20}$ The wings of dragonflies possess similar antiwetting properties but exhibit a wider range of bactericidal activity. To the best of our knowledge, there have been no systematic studies performed that have compared the characteristics of dragonfly wings across a broad range of species. Here, we present the surface properties of the wings of different dragonfly species as a function of the insects' taxa, geography, habitat, and lifestyle characteristics including migratory and foraging behaviors. The results of this research will significantly contribute to an understanding of surface architectural features that are optimal for the biomimetic design of surfaces where microbial colonization is a concern. ${ }^{21}$

The nanoarchitecture and wettability of the dragonfly's wing epicuticle may vary because of different lifestyle requirements, such as their feeding and migratory habits. For example, the foraging behavior of a dragonfly can be classified by two main strategies. "Hawkers" tend to remain in flight, patrolling their territories, and hunting their prey from the air, whereas "perchers" spend most of their time at rest, only taking flight once they spot their prey. ${ }^{22,23}$ Hawkers, similar to migratory species that spend long periods in flight, are likely to have developed a lower requirement for a highly antifouling and antibacterial wing epicuticle than perchers. It was also hypothesized that the opportunistic species that inhabit still water and temporary pools such as ponds or ditches have evolved to have decreased wing wettability compared to those that prefer to inhabit fast running water environments. Insects that inhabit still water environments tend to have short life cycles, sometimes as little as $8-10$ weeks from egg to adult, because of the temporary nature of their homes. In contrast, riverine species usually take more than a year to reach maturity. ${ }^{24}$

\section{RESULTS}

2.1. Dragonfly Collection and Scope of Study. Dragonfly species were collected from Melbourne, Australia, and the Baix Ebre and Terra Alta regions of Catalonia, Spain (Table 1). Seven species from three families and two geographical locations were studied. Fourier-transform infrared (FTIR) microspectroscopy was used to compare the chemical composition of each wing membrane. The wettability of the wing surface was determined through static water contact angles (WCAs) taken across the wing surfaces as well as the analysis of high-speed videos of bouncing water droplets. To investigate the wing surface nanoarchitecture, scanning electron microscopy (SEM) and tilted SEM images were analyzed. These data were then correlated with the taxa, geography, habitat, size, and migratory and foraging behaviors of the dragonfly species.
2.2. FTIR Microspectroscopic Analysis of Dragonfly Wing. The infrared spectral maps of each wing sample were obtained using focal plane array (FPA)-FTIR microspectroscopy (Figures 1 and $\mathrm{S} 1$ ). The spectra from each sample were

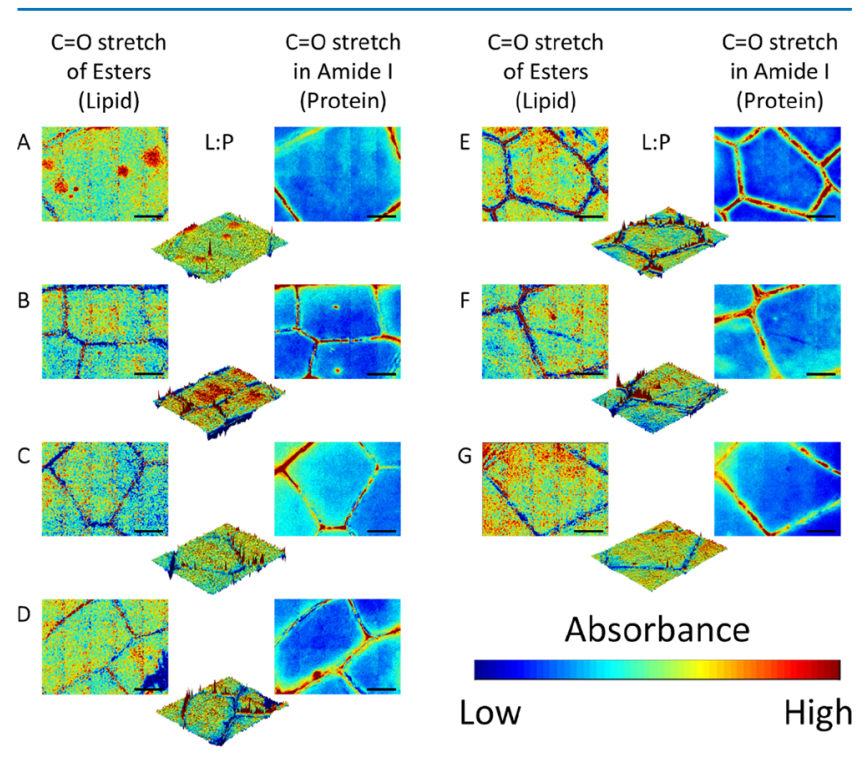

Figure 1. Chemical compositions of the wing membranes of seven species of dragonfly from three families, characterized through FTIR microspectroscopy. (A) Austrothemis nigrescens, (B) Orthetrum chrysostigma, (C) Trithemis annulata, (D) Sympetrum fonscolombii, (E) Anax parthenope, (F) Anax imperator, and (G) Onychogomphus forcipatus. In the $2 \mathrm{D}$ contour plots, lipid and protein distributions were determined through absorbance at the $\mathrm{C}=\mathrm{O}$ stretching band (1750$\left.1720 \mathrm{~cm}^{-1}\right)$ and amide I band $\left(1705-1600 \mathrm{~cm}^{-1}\right)$, respectively. The red areas represent higher absorbance in the bands and thus higher concentrations, whereas the blue areas represent lower concentrations. The three-dimensional (3D) contour plots of the lipid/protein ratio show the areas of relatively higher lipid concentration in red and areas of higher protein concentration in blue. Scale bars $=200 \mu \mathrm{m}$.

broadly similar, containing three major bands or band groups at $3480-3230,3000-2800,1750-1480 \mathrm{~cm}^{-1}$ which correspond to hydroxyl, alkyl hydrocarbons, and ester carbonyl groups, respectively (Figure S1). ${ }^{33-35}$ The presence of $\mathrm{C}-\mathrm{H}$ stretching bands, with a prevalence of methylene bands, indicate longchain aliphatic hydrocarbons typical of waxes. ${ }^{33,36}$ The spectra of all wings were dominated by amide I and amide II absorption bands because of $\mathrm{C}=\mathrm{O}$ bond stretching coupled to $\mathrm{N}-\mathrm{H}$ bending $\left(1695-1610 \mathrm{~cm}^{-1}\right)$ and $\mathrm{C}-\mathrm{N}$ stretching coupled to $\mathrm{N}-\mathrm{H}$ bending $\left(1575-1480 \mathrm{~cm}^{-1}\right)$, respectively. ${ }^{35}$ The presence of amide groups can be attributed to the chitin and protein components of the wings, as they represent the major structural components of the insect cuticle. 


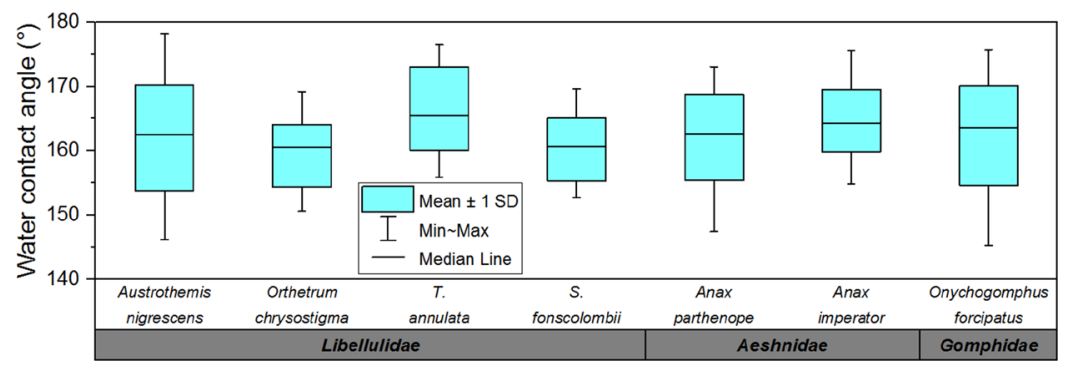

Figure 2. Wettability of the wing surface of seven species of dragonfly from three families. WCAs were measured using a sessile drop at 17 points across the wing surface. Figure created using OriginPro 2015 (OriginLab Corporation, Northampton, MA).

The two-dimensional (2D) spectral maps of the dragonfly wings showed spatial variations in the intensities of ester carbonyl (lipid component) and amide I (protein component) peaks (Figure 1). The lipid and protein compositions of the wing membrane were determined through FPA-FTIR. The lipid concentration was indicated by the absorbance over the wavelength range $1750-1720 \mathrm{~cm}^{-1}$, which is the representative of the $\mathrm{C}=\mathrm{O}$ stretch of esters, whereas the protein concentration was determined by the absorbance in the range $1705-1600 \mathrm{~cm}^{-1}$, which is representative of the amide I absorption band. The lipids/waxes distributions were similar across the specimens, with the lower concentrations being found in the wing veins, indicated in blue, compared to the membranes (Figure 1). Microdomains that contained a high concentration of lipids/waxes, represented in red, were observed in the membrane of Austrothemis nigrescens as well as Anax imperator (Figure 1A,F). Protein distribution was relatively homogenous across each dragonfly wing specimen and inversely reflected the lipid distribution with higher concentrations in the vein and lower concentrations in the membrane. Microdomains of highly concentrated protein regions were present in the Orthetrum chrysostigma sample (Figure 1A,B).

The $\mathrm{C}-\mathrm{H}$ stretching region $\left(2840-3000 \mathrm{~cm}^{-1}\right)$ represented the symmetric $\left(\nu_{\mathrm{s}}\right)$ and antisymmetric $\left(\nu_{\mathrm{as}}\right)$ stretching vibrations of $\mathrm{CH}_{2}$ and $\mathrm{CH}_{3}$ functional groups. The presence of $\mathrm{C}-\mathrm{H}$ stretching bands with a prevalence of methylene bands in all seven dragonfly wing samples indicated the presence of long-chain aliphatic hydrocarbons (Figure S1). ${ }^{33,36}$ The intensity of these $\mathrm{C}-\mathrm{H}$ stretching bands, which provides an indication of the amount of waxes present on the wings, was seen to vary between species. The wings of T. annulata, Anax imperator, and Onychogomphus forcipatus appeared to have the highest absorbance within these bands, whereas Austrothemis nigrescens contained the lowest wax levels (Figure S1).

2.3. Surface Wettability. The wettability of the wing surface of the seven dragonfly specimens was evaluated via the measurement of receding WCAs across the wings (Figure 2). Wing surface WCA measurements were reasonably consistent across all seven species and above the accepted threshold for superhydrophobicity $\left(>150^{\circ}\right)$. A random intercept model, generated using HLM (version 7.03), suggests that interspecies variation accounts for only $9 \%$ of overall variation (Table S1).

2.4. Bouncing Droplet Behavior. Superhydrophobic surfaces can cause water droplets coming into contact to bounce. On rough surfaces, these droplets can undergo a phenomenon known as the "pancake" bouncing. ${ }^{37,38}$ Pancake bouncing occurs as droplets flatten and spread on impact with the surface before lifting off in a flattened pancakelike shape. Droplets are classified by the $Q$ ratio, which is the ratio between the lateral extension diameter of the droplet as it detaches from the surface $\left(d_{\text {jump }}\right)$ and the maximum diameter of water droplet on the surface $\left(d_{\max }\right) . Q>0.8$ indicates a pancake bounce. ${ }^{37-39}$

All specimens exhibited the bouncing droplet behavior shown in Figure 3 and Movie S1-S7; however, total contact

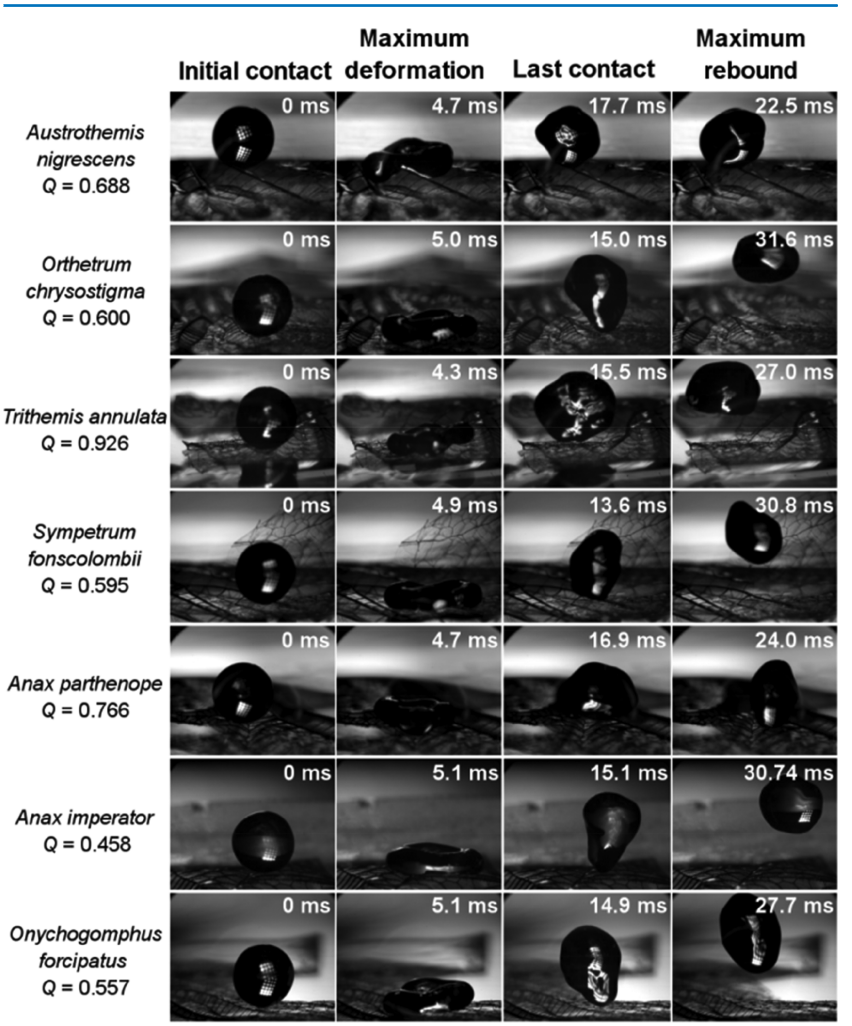

Figure 3. Bouncing water droplets on the wings of seven species of dragonfly from three families. Selected snapshots show the droplet morphology over the course of one bounce at: the initial point of contact; when the droplet reached maximum deformation on the wing surface; the last point of contact; and at maximum rebound. The timestamps show how many milliseconds it took to reach the displayed morphology after the initial point of contact. The $Q$ ratio represents the degree of "pancaking", with $Q>0.8$ indicating a pancake bounce.

time varied between species ranging from $S$. fonscolombii (13.4 $\pm 0.9 \mathrm{~ms}$ ) to Austrothemis nigrescens $(18.7 \pm 1.4 \mathrm{~ms}$ ) (Figure 3 and Table S2). The theoretical contact time of a bouncing water droplet $(\tau)$ on a superhydrophobic surface can be calculated using the properties of the water droplet through the following equation 40

$$
\tau \approx\left(\rho R_{0}{ }^{3} / \gamma\right)^{1 / 2}
$$


where $\rho$ is the density of water, assumed as $997 \mathrm{~kg} \mathrm{~m}^{-3}$ and $\gamma$ is the surface tension of water, accepted as $7.2 \times 10^{-2} \mathrm{~N} \mathrm{~m}^{-1} . R_{0}$ is the radius of the water droplet, in this experiment, measured as $1.3 \times 10^{-3} \mathrm{~m}$. Hence, the theoretical droplet contact time is calculated to be $\tau=5.5 \mathrm{~ms}$. This value is much lower than the observed contact times on the surface of the wings of all seven species of dragonflies (Table S2).

Most replicates exhibited directional droplet bouncing, however, the direction was not consistent across the individual wing surface with a combination of dorsal-ventral and anterior-posterior directionality observed (Table S2). It appeared that directionality of bounce was primarily affected by the presence of nonuniform corrugations in the macrostructure of the wing, causing ridges and valleys, which resulted in an angular bouncing of the droplet.

It was found that there was a variation between species in the degree of pancake bouncing, with the T. annulata $(Q=0.926 \pm$ 0.003 ) sample being the only species that displayed true pancake bouncing above the accepted threshold $Q>0.8$. The Anax parthenope sample showed near pancake bouncing $(Q=$ $0.766 \pm 0.270)$. The $Q$ values of the remaining dragonfly specimens were below 0.7 , indicating conventional bouncing, with the Anax imperator wing exhibiting the lowest value $(Q=$ $0.458 \pm 0.062$ ).

2.5. Wing Surface Nanoarchitecture. Top-view and tilted SEM images determined the nanopillar height, diameter, and density of nanofeatures and free-standing pillars for each dragonfly wing sample (Figures 4 and S3). A wing surface nanoarchitecture consisting of an irregular array of single and clustering nanopillars was observed on all dragonflies (Figure 4). Average nanopillar height ranged from $236 \pm 39 \mathrm{~nm}$ on the wing Onychogomphus forcipatus to $307 \pm 34 \mathrm{~nm}$ on the wing of Austrothemis nigrescens (Figure S2A and Table S3). The

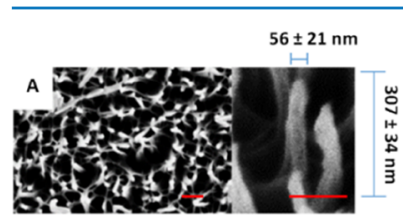

$61 \pm 26 \mathrm{~nm}$

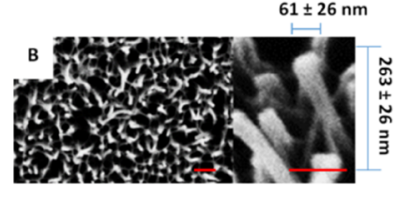

$56 \pm 22 \mathrm{~nm}$

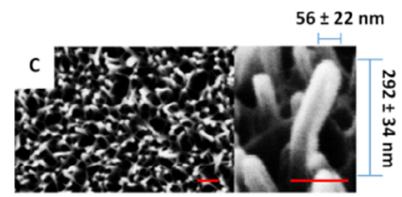

$58 \pm 22 \mathrm{~nm}$

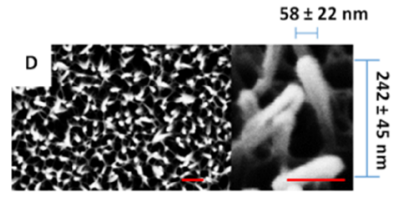

Figure 4. Top-view (left) and tilted (right) images of nanopillar arrangements on the wing epicuticle of seven species of dragonfly from three families. (A) Austrothemis nigrescens, (B) Orthetrum chrysostigma, (C) T. annulata, (D) S. fonscolombii, (E) Anax parthenope, (F) Anax imperator, and (G) Onychogomphus forcipatus. Scale bar represents 200 $\mathrm{nm}$ (top-view) and $100 \mathrm{~nm}$ (tilted). diameter of the free-standing pillars were similar across the seven individuals, ranging from $41 \pm 5 \mathrm{~nm}$ on the wing of $S$. fonscolombii to $51 \pm 5 \mathrm{~nm}$ on the wing of Orthetrum chrysostigma (Figure S2B and Table S3). The density of all nanopillars, clustered and free-standing, was measured through Image J analysis and ranged from $47 \pm 3$ to $63 \pm 4$ (nanopillars/ $\mu \mathrm{m}^{2}$ ) (Figure S3C and Table S3). These measurements were compared to the sophisticated neural network analysis, which isolated free-standing pillars, presenting a comparable trend that suggests that the degree of pillar clustering was somewhat similar across seven individuals (Figure S2C).

Statistical analysis using random intercept models suggested interspecies variance of nanopillar width and height accounted for only 25 and $34 \%$ of the total variation observed, respectively (Table S1). This relatively low percentage of overall variation is partly because of the heterogeneous nature of the unique nanoarchitecture as observable in the top-view SEM images (Figure 4). There was a large interspecies variation between the density of nanofeatures, accounting for $77 \%$ of the overall variance (Table S1). However, further exploratory analysis found no significant relationship between the family, geographic location, habitat, or migratory and foraging behaviors of the dragonfly individuals and nanopillar width or height (Table S3).

\section{DISCUSSION}

The relationship between the taxonomy, geography, habitat preference, and migratory and foraging behaviors of seven dragonfly species, inhabiting Australian and European environments, and their corresponding surface characteristics were determined. Infrared microspectroscopy, WCA analysis, and droplet jumping behavior and SEM were used to characterize, respectively, the chemistry, wettability, and nanoarchitecture of dragonfly wing epicuticles.

The chemical compositions of the wing epicuticle were reasonably consistent across all seven species of dragonfly. The representative spectra from each wing sample have clear $\mathrm{C}-\mathrm{H}$ stretching bands, with a prevalence of methylene bands (Figure S1), which indicate long-chain aliphatic hydrocarbons. ${ }^{33,36}$ These results align with previous reports that demonstrate the presence of epicuticular waxes on the surface of dragonfly wings. ${ }^{3-5} 2 \mathrm{D}$ and $3 \mathrm{D}$ contour maps showed that lipids/waxes were generally more concentrated in the membrane sections, whereas the protein concentration was greater on the veins of the wings (Figure 1). As these features were consistent across all species tested, the key chemical components of the wings are likely highly conserved, suggesting that the composition is important for wing functionality. The conservation of the chemical compositions is also important throughout the life of the dragonfly, as their wings do not regenerate. They have been shown to possess remarkable stability, remaining intact for up to 40 years. ${ }^{4}$ However, the intensity of the $\mathrm{C}-\mathrm{H}$ stretching bands varied between species, indicating that the quantity of lipids/waxes present on the wings varied between species. Additionally, subtle differences in the $2 \mathrm{D}$ chemical distribution maps of the wing membrane region suggest that the distribution is not homogenous.

The superhydrophobicity of the wing surfaces was also found to be well-conserved between all seven dragonfly species. No relationship was found between wing wettability and taxonomy, habitat, and behavioral and lifestyle traits of the dragonflies studied. This contradicts our initial hypothesis and differs from similar work with cicadas, which suggested a relationship 
between taxonomy and wettability. ${ }^{18}$ This further highlights the importance of the antiwetting and self-cleaning properties of dragonflies' wings to their survival. This was seen in other insects with a high wing surface/body mass ratio, where the accumulation of contaminants can significantly hinder their flying abilities. The dragonflies' unique wing surfaces likely evolved in an early ancestor, supported by the similar wing surface nanoarchitecture found on the wing membrane epicuticle of damselflies, a close relative of the dragonfly also within the order Odonata. ${ }^{4,41}$

To the best of our knowledge, this is the first study to examine droplet bouncing behavior on the surface of the dragonfly insect wings consisting of nanopillars. The conserved superhydrophobicity across all seven dragonfly specimens resulted in water droplet bouncing behavior being present on all samples. One specimen, T. annulata, displayed true pancake bouncing above the accepted threshold, whereas other wing surfaces ranged from clearly conventional bouncing to near pancake bouncing. Droplet contact times were approximately threefold longer than the calculated theoretical time and significantly higher than synthetic surfaces that exhibit similar pancake bouncing behavior. ${ }^{37,38}$ This extended droplet contact time is likely a function of the dynamic nature of the dragonfly wing surface which displays bending upon droplet impact. Dragonfly wings are flexible and are able to rapidly deform, allowing them to withstand stresses associated with flight. ${ }^{42,43}$ We propose that this flexibility may also help absorb the impact of water droplets to the membrane, mitigating the risk of damage. Comparatively, synthetic surfaces examined in previous droplet bouncing studies are typically flat or uniformly angled with limited or no flexibility in the macrostructure. ${ }^{37,38,40,44,45}$ While we focused on the wing surface nanoarchitecture in this study, it is likely that interactions of macroscale features such as membrane corrugations, veins, and microtrichia contribute to the behavior of impacting water droplets. These findings warrant further work to understand more about this complex natural system.

The unique pattern of nonuniform, irregularly organized nanopillars was present on all seven dragonfly species studied. Surprisingly, the height and peak width of the nanopillars were very similar across all individuals despite the seemingly random organization. The density of peaks did differ between species, which reflects the observable differences in nanostructured patterns when viewing top-view SEM images (Figure 4); however, these changes appeared unrelated to lifestyle or behavioral factors. Interestingly, it has previously been demonstrated that wing macrostructures similarly do not correlate with the preference for still or flowing water habitats. ${ }^{46}$ Whereas the wings of migratory dragonfly species have been shown to differ in macrostructure, possessing an extra lobe and generally being larger and smoother than nonmigratory species. ${ }^{16,47}$

It should be noted that the dragonfly species studied here were represented by only one individual, and therefore this study serves as an initial work to highlight possible relationships between the dragonfly wing epicuticle properties, including their chemical composition, wettability and nanoarchitecture, and the dragonfly characteristics. The results presented here should be revisited in future studies as more information becomes available regarding the unique surface properties of dragonfly wings.

\section{CONCLUSIONS}

This work provides a systematic study of seven species of dragonfly collected from Australia and Europe. Various lifestyle and physiological characteristics were considered for their potential relationships with various wing epicuticle properties, including chemical composition, wettability, and nanoarchitecture. Overall, there were no clear and outstanding correlations between lifestyle or wing surface characteristics. We found that the unique arrays of nanopillars on the waxy epicuticular layer of the wings were present in all studied species and that the chemical composition of this layer was consistent between different wing samples. The resultant superhydrophobicity was well-conserved, suggesting that this unique nanoarchitecture likely evolved in an early ancestor because of the importance of the antiwetting and self-cleaning properties to dragonfly survival. Despite the conservation of wing membrane chemistry and hydrophobicity, there were slight differences in droplet contact behavior which may reflect variance in wing macrostructures. The height and width of the nanopillars were relatively similar, whereas the density appeared to differ between species. This study provides a framework for future research in the emerging field of bio-inspired design of surfaces and may support the development of antiwetting surfaces for use in biomedicine, infrastructure, aviation, and marine design applications.

\section{MATERIALS AND METHODS}

5.1. Dragonfly Collection and Sample Preparation. Seven species of dragonfly were collected from Melbourne, Australia, and the Baix Ebre and Terra Alta regions of Catalonia, Spain (Table 1). The wings of each specimen were removed from the body aseptically and stored under dark conditions at room temperature (ca. $22{ }^{\circ} \mathrm{C}$ ) in sterile polystyrene Petri dishes (Techno Plas) until required. The distal-posterior regions of the forewings were dissected into approximately $5 \mathrm{~mm} \times 5 \mathrm{~mm}$ squares using a sterile surgical blade.

5.2. Scanning Electron Microscopy. High-resolution scanning electron micrographs were obtained at $3 \mathrm{kV}$ under $20000 \times, 40000 \times$, and $70000 \times$ magnification using a Zeiss SUPRA 40VP field-emission SEM (Carl Zeiss NTS GmbH, Oberkochen, BW, Germany). Wing samples were coated with thin gold films of $7.5 \mathrm{~nm}$ in thickness, according to the manufacturer's instructions, using a MP-19020NCTR NeoCoater, before viewing with the microscope. Wing excavation was performed using a FEI Helios NanoLab 600 focused ion beam scanning electron microscope, with a $30 \mathrm{kV} \mathrm{Ga}^{+}$ion beam at a current of $9.7 \mathrm{pA}$ and under a vacuum of $1 \times 10^{-3} \mathrm{~Pa}$.

Scanning electron micrographs were analyzed using Image J software (version 1.50i). The color threshold for binary SEM images was adjusted and the particles were analyzed. Particles with a diameter below $30 \mathrm{~nm}$ were removed as artefacts. The nanofeature density, inclusive of free-standing and clustering nanopillars, was determined using particle analysis, with measurements taken over six regions, $1.5 \mu \mathrm{m} \times 2 \mu \mathrm{m}$ in area, on each of the wing surface for each dragonfly. The density of free-standing nanopillars was determined through neural network analysis as previously described. ${ }^{48}$

Nanopillar tip diameters were measured manually using ImageJ software because an automated approach was found to be unsuitable because of the natural bending and clustering of the nanopillars. The width of 17 nanopillars across three 
regions of the wing was measured for each dragonfly. The height of nanopillars was determined by tilting the samples at a $45^{\circ}$ angle, with images being obtained using the high-resolution SEM capabilities of the electron beam lithography tool (RAITH150 Two, Raith GmBH) at $5 \mathrm{kV}$. The height of seventeen nanopillars over two sections of the wing were measured for each dragonfly. Images were captured at the magnification levels previously stated.

5.3. IR Microspectroscopy. The dragonfly wings were cut into rectangular sections using a surgical blade. Sections were then fixed between aluminum support frames using polyimide (Kapton) tape to fix both sides of the section ready for subsequent spectral data collection. FPA-FTIR spectral images of the dragonfly wings were acquired using the Infrared Microspectroscopy Beamline, Australian Synchrotron (Clayton, Australia) and a Bruker HYPERION 2000 FTIR microscope (Bruker Optik GmbH, Ettlingen, Germany), equipped with a liquid- $\mathrm{N}_{2}$ cooled $64 \times 64$ element FPA detector and a $15 \times$ objective lens $(\mathrm{NA}=0.4)$, which was coupled to a Vertex 70/ $70 \mathrm{v}$ FTIR spectrometer with an internal Globar IR source (Bruker Optik GmbH, Ettlingen, Germany). The spectra were collected in transmission mode within a $4000-800 \mathrm{~cm}^{-1}$ spectral region as a single FTIR image covering a sampling area of $170 \mu \mathrm{m} \times 170 \mu \mathrm{m}$. Each FTIR spectral image comprises a $32 \times 32$ array of spectra resulting from binning the signal from each square of four detectors on the $64 \times 64$ element FPA array. As a consequence, a single spectrum from each FTIR image represented the chemical information acquired from ca. $5.4 \mu \mathrm{m} \times 5.4 \mu \mathrm{m}$ area on the wing membrane.

For each wing section, high-quality FTIR spectral images were collected at $4 \mathrm{~cm}^{-1}$ resolution with 64 coadded scans. Blackman-Harris 3-term apodization, power-spectrum phase correction, and a zero-filling factor of 2 were set as the default acquisition parameters using OPUS 7.2 imaging software suite (Bruker). Background measurements were taken prior to sample spectral images, by focusing the beam through an air gap between the wing sections under the same acquisition parameters. The lipid and protein distribution present in the wing samples were approximated by integrating the ester carbonyl stretching band $\left(1720-1750 \mathrm{~cm}^{-1}\right)$ and amide I band $\left(1705-1600 \mathrm{~cm}^{-1}\right)$, respectively, using the OPUS software.

5.4. WCA Measurements. The surface wettability of the wings was examined by measuring the receding WCA, using the sessile drop method, at the point prior to droplet elongation as the tip was drawn away from the surface. The contact angle measurements were carried out in air using an FTA1000c equipped with a nanodispenser (First Ten Ångstroms, Inc., Portsmouth, VA, USA). Seventeen measurements were taken across the entire surface of each dragonfly forewing. Measurements where the water droplet adhered to the surface of the wing were excluded, as this likely resulted because of wing damage.

5.5. Bouncing Droplet Behavior. Bouncing water droplets were studied using a Phantom v2512 high-speed camera at $28000 \mathrm{fps}$ and $768 \times 768$ resolution. Droplets were released $13 \mathrm{~mm}$ above the wing surfaces at room temperature using an FTA1000c equipped with a nanodispenser (First Ten Ångstroms, Inc., USA). Water droplet volume was $9.6 \pm 0.8 \mu \mathrm{L}$, with a diameter of approximately $2.6 \pm 0.08 \mathrm{~mm}$. The droplet bouncing behavior was characterized as pancake or conventional bouncing. This was determined by calculating the ratio $(Q)$ between the lateral extension diameter of the droplet as it detached from the surface $\left(d_{\text {jump }}\right)$ and the maximum diameter of the water droplet on the surface $\left(d_{\max }\right)$, where $Q>0.8$ indicated a pancake bounce. ${ }^{37-39}$ The Weber number was determined for each sample using the equation $W e=\rho v^{2} r_{0} / \gamma$, where $\rho$ is the liquid density, $v$ is the impact velocity, $r_{0}$ is the droplet radius, and $\gamma$ is the surface tension. For all our experiments, $W e=9.26 \pm 0.27$.

5.6. Statistical Analysis. SPSS version 25 (IBM Corp., Armonk, NY) was used to test WCA and nanopillar height, diameter, and density measures for normality using $Q-Q$ plots of the residuals. Hierarchical linear modelling was performed using the student edition of HLM version 7.03 (Scientific Software International, Skokie, IL), with individual measurements as level 1 data and species as level 2 data. The family was recoded as binary variables so that each of the three families was compared to the combination of the other two families. A random intercept model was used to assess the proportion of variation attributed to interspecies differences. An exploratory analysis was used to identify possible level 2 predictors by $t$ values. Where $t$ values approached $\pm 2, p$ values from a final estimation of fixed effects were considered to evaluate the likelihood of a relationship. It is worth noting that this study was limited with regard to sample sizes. Each dragonfly species was represented by a single individual. The variation and imperfections inherent in this type of natural surface also meant that the nanopillar height and diameter had to be measured manually; therefore, a limited number of measurements were included.

\section{ASSOCIATED CONTENT}

\section{Supporting Information}

The Supporting Information is available free of charge on the ACS Publications website at DOI: 10.1021/acsomega.8b00776.

Bouncing water droplet behavior on the wings of seven species of dragonfly: Austrothemis nigrescens, Orthetrum chrysostigma, T. annulata, S. fonscolombii, Anax parthenope, Anax imperator, and Onychogomphus forcipatus; average IR spectra of an area of the wing membrane of seven dragonfly species; comparative distributions of nanopillar heights and free-standing nanopillar diameters on the wings of seven species of dragonfly; proportion of variance attributed to interspecies variation; and summary of bouncing droplets on wing surfaces (PDF) Bouncing water droplet behavior on the wings of Austrothemis nigrescens (AVI)

Bouncing water droplet behavior on the wings of Orthetrum chrysostigma (AVI)

Bouncing water droplet behavior on the wings of T. annulata (AVI)

Bouncing water droplet behavior on the wings of S. fonscolombii (AVI)

Bouncing water droplet behavior on the wings of Anax parthenope (AVI)

Bouncing water droplet behavior on the wings of Anax imperator (AVI)

Bouncing water droplet behavior on the wings of Onychogomphus forcipatus (AVI)

\section{AUTHOR INFORMATION}

\section{Corresponding Author}

*E-mail: elena.ivanova@rmit.edu.au. Phone: +61 392145137. ORCID $\odot$

Denver Linklater: 0000-0003-1433-3685 
Marco Werner: 0000-0001-5433-8443

Vladimir A. Baulin: 0000-0003-2086-4271

Elena P. Ivanova: 0000-0002-5509-8071

Author Contributions

$\nabla_{\text {S.C. }}$ and S.O. contributed equally to this work.

Notes

The authors declare no competing financial interest.

\section{ACKNOWLEDGMENTS}

This research was undertaken in part on the Infrared Microspectroscopy Beamline at the Australian Synchrotron, part of ANSTO.

\section{REFERENCES}

(1) Mainwaring, D. E.; Nguyen, S. H.; Webb, H.; Jakubov, T.; Tobin, M.; Lamb, R. N.; Wu, A. H.-F.; Marchant, R.; Crawford, R. J.; Ivanova, E. P. The Nature of Inherent Bactericidal Activity: Insights from the Nanotopology of Three Species of Dragonfly. Nanoscale 2016, 8, 6527-6534.

(2) Ivanova, E. P.; Hasan, J.; Webb, H. K.; Truong, V. K.; Watson, G. S.; Watson, J. A.; Baulin, V. A.; Pogodin, S.; Wang, J. Y.; Tobin, M. J.; Löbbe, C.; Crawford, R. J. Natural Bactericidal Surfaces: Mechanical Rupture of Pseudomonas aeruginosa Cells by Cicada Wings. Small 2012, 8, 2489-2494.

(3) Nguyen, S. H. T.; Webb, H. K.; Hasan, J.; Tobin, M. J.; Crawford, R. J.; Ivanova, E. P. Dual Role of Outer Epicuticular Lipids in Determining the Wettability of Dragonfly Wings. Colloids Surf., B 2013, 106, 126-134.

(4) Nguyen, S. H.; Webb, H. K.; Hasan, J.; Tobin, M. J.; Mainwaring, D. E.; Mahon, P. J.; Marchant, R.; Crawford, R. J.; Ivanova, E. P. Wing Wettability of Odonata Species as a Function of Quantity of Epicuticular Waxes. Vib. Spectrosc. 2014, 75, 173-177.

(5) Ivanova, E. P.; Nguyen, S. H.; Webb, H. K.; Hasan, J.; Truong, V. K.; Lamb, R. N.; Duan, X.; Tobin, M. J.; Mahon, P. J.; Crawford, R. J. Molecular Organization of the Nanoscale Surface Structures of the Dragonfly Hemianax papuensis Wing Epicuticle. PLoS One 2013, 8, No. e67893.

(6) Hasan, J.; Webb, H. K.; Truong, V. K.; Watson, G. S.; Watson, J. A.; Tobin, M. J.; Gervinskas, G.; Juodkazis, S.; Wang, J. Y.; Crawford, R. J.; Ivanova, E. P. Spatial Variations and Temporal Metastability of the Self-Cleaning and Superhydrophobic Properties of Damselfly Wings. Langmuir 2012, 28, 17404-17409.

(7) Watson, J. A.; Hu, H.-M.; Cribb, B. W.; Watson, G. S. Antiwetting on insect cuticle-structuring to minimise adhesion and weight. In On Biomimetics [Online], 1st ed.; Pramatarova, D. L., Ed.; InTech: London, England, 2011; pp 395-418. http://www. intechopen.com/books/on-biomimetics/anti-wetting-oninsect-cuticlestructuring-to-minimise-adhesion-and-weight (accessed Sept 15, 2017).

(8) Ivanova, E. P.; Hasan, J.; Webb, H. K.; Gervinskas, G.; Juodkazis, S.; Truong, V. K.; Wu, A. H. F.; Lamb, R. N.; Baulin, V. A.; Watson, G. S. Bactericidal Activity of Black Silicon. Nat. Commun. 2013, 4, 2838.

(9) Tripathy, A.; Sen, P.; Su, B.; Briscoe, W. H. Natural and Bioinspired Nanostructured Bactericidal Surfaces. Adv. Colloid Interface Sci. 2017, 248, 85-104.

(10) Gangadoo, S.; Chandra, S.; Power, A.; Hellio, C.; Watson, G. S.; Watson, J. A.; Green, D. W.; Chapman, J. Biomimetics for Early Stage Biofouling Prevention: Templates from Insect Cuticles. J. Mater. Chem. B 2016, 4, 5747-5754.

(11) Bhadra, C. M.; Truong, V. K.; Pham, V. T. H.; Al Kobaisi, M.; Seniutinas, G.; Wang, J. Y.; Juodkazis, S.; Crawford, R. J.; Ivanova, E. P. Antibacterial Titanium Nano-Patterned Arrays Inspired by Dragonfly Wings. Sci. Rep. 2015, 5, 16817.

(12) Pham, V. T. H.; Truong, V. K.; Orlowska, A.; Ghanaati, S.; Barbeck, M.; Booms, P.; Fulcher, A. J.; Bhadra, C. M.; Buividas, R.; Baulin, V. "Race for the Surface": Eukaryotic Cells can Win. ACS Appl. Mater. Interfaces 2016, 8, 22025-22031.
(13) Tripathy, A.; Sreedharan, S.; Bhaskarla, C.; Majumdar, S.; Peneti, S. K.; Nandi, D.; Sen, P. Enhancing the Bactericidal Efficacy of Nanostructured Multifunctional Surface Using an Ultrathin Metal Coating. Langmuir 2017, 33, 12569-12579.

(14) Jongerius, S. R.; Lentink, D. Structural Analysis of a Dragonfly Wing. Exp. Mech. 2010, 50, 1323-1334.

(15) Rajabi, H.; Ghoroubi, N.; Stamm, K.; Appel, E.; Gorb, S. N. Dragonfly Wing Nodus: A One-Way Hinge Contributing to the Asymmetric Wing Deformation. Acta Biomater. 2017, 60, 330-338.

(16) Wagner, T.; Neinhuis, C.; Barthlott, W. Wettability and Contaminability of Insect Wings as a Function of their Surface Sculptures. Acta Zool. 1996, 77, 213-225.

(17) Holdgate, M. The Wetting of Insect Cuticles by Water. J. Exp. Biol. 1955, 32, 591-617.

(18) Oh, J.; Dana, C. E.; Hong, S.; Román, J. K.; Jo, K. D.; Hong, J. W.; Nguyen, J.; Cropek, D. M.; Alleyne, M.; Miljkovic, N. Exploring the Role of Habitat on the Wettability of Cicada Wings. ACS Appl. Mater. Interfaces 2017, 9, 27173-27184.

(19) Hasan, J.; Webb, H. K.; Truong, V. K.; Pogodin, S.; Baulin, V. A.; Watson, G. S.; Watson, J. A.; Crawford, R. J.; Ivanova, E. P. Selective Bactericidal Activity of Nanopatterned Superhydrophobic Cicada Psaltoda claripennis Wing Surfaces. Appl. Microbiol. Biotechnol. 2013, 97, 9257-9262.

(20) Pogodin, S.; Hasan, J.; Baulin, V. A.; Webb, H. K.; Truong, V. K.; Phong Nguyen, T. H.; Boshkovikj, V.; Fluke, C. J.; Watson, G. S.; Watson, J. A.; Crawford, R. J.; Ivanova, E. P. Biophysical Model of Bacterial Cell Interactions with Nanopatterned Cicada Wing Surfaces. Biophys. J. 2013, 104, 835-840.

(21) Elbourne, A.; Crawford, R. J.; Ivanova, E. P. Nano-Structured Antimicrobial Surfaces: From Nature to Synthetic Analogues. J. Colloid Interface Sci. 2017, 508, 603-616.

(22) Bomphrey, R. J.; Nakata, T.; Henningsson, P.; Lin, H.-T. Flight of the Dragonflies and Damselflies. Philos. Trans. R. Soc., B 2016, 371, 20150389.

(23) Corbet, P. S. Dragonflies: Behavior and Ecology of Odonata, 1st ed.; Comstock Publishing Associates: Ithaca, NY, 1999.

(24) Theischinger, G.; Hawking, J. The Complete Field Guide to Dragonflies of Australia, 1st ed.; CSIRO Publishing: Collingwood, Australia, 2006; pp 282-283.

(25) Samways, M. J. Dragonflies and Damselflies of South Africa, 1st ed.; Pensoft: Sofia, Bulgaria, 2008; pp 112-203.

(26) Boudot, J.-P.; Clausnitzer, V.; Samraoui, B.; Suhling, F.; Dijkstra, K.-D. B.; Schneider, W. Orthetrum chrysostigma. The IUCN Red List of Threatened Species, 2016.

(27) Boudot, J.-P.; Clausnitzer, V.; Ferreira, S.; Suhling, F.; Dijkstra, K.-D. B.; Schneider, W.; Samraoui, B. Trithemis annulata. The IUCN Red List of Threatened Species, 2016.

(28) Smallshire, D.; Swash, A. Britain's Dragonflies: A Field Guide to the Damselflies and Dragonflies of Britain and Ireland, 3rd ed.; Princeton University Press: Princeton, NJ, 2014.

(29) Mitra, A. Anax parthenope. The IUCN Red List of Threatened Species, 2013.

(30) Mitra, A. Anax imperator. The IUCN Red List of Threatened Species, 2016.

(31) Gibbons, B. Field Guide to Insects of Britain and Northern Europe, 1st ed.; Crowood: Ramsbury, England, 2011; pp 116-179.

(32) Kalkman, V. J. Onychogomphus forcipatus. The IUCN Red List of Threatened Species, 2014.

(33) Coury, C.; Dillner, A. M. A Method to Quantify Organic Functional Groups and Inorganic Compounds in Ambient Aerosols Using Attenuated Total Reflectance FTIR Spectroscopy and Multivariate Chemometric Techniques. Atmos. Environ. 2008, 42, 59235932.

(34) Lasch, P.; Boese, M.; Pacifico, A.; Diem, M. FT-IR Spectroscopic Investigations of Single Cells on the Subcellular Level. Vib. Spectrosc. 2002, 28, 147-157.

(35) Barth, A. Infrared Spectroscopy of Proteins. Biochim. Biophys. Acta, Bioenerg. 2007, 1767, 1073-1101. 
(36) Coates, J. Interpretation of Infrared Spectra, a Practical Approach. Encyclopedia of Analytical Chemistry, 1st ed.; Wiley \& Sons: Chichester, England, 2000; pp 10815-10837.

(37) Liu, Y.; Moevius, L.; Xu, X.; Qian, T.; Yeomans, J. M.; Wang, Z. Pancake Bouncing on Superhydrophobic Surfaces. Nat. Phys. 2014, 10, 515-519.

(38) Song, J.; Gao, M.; Zhao, C.; Lu, Y.; Huang, L.; Liu, X.; Carmalt, C. J.; Deng, X.; Parkin, I. P. Large-Area Fabrication of Droplet Pancake Bouncing Surface and Control of Bouncing State. ACS Nano 2017, 11, 9259-9267.

(39) Moevius, L.; Liu, Y.; Wang, Z.; Yeomans, J. M. Pancake Bouncing: Simulations and Theory and Experimental Verification. Langmuir 2014, 30, 13021-13032.

(40) Okumura, K.; Chevy, F.; Richard, D.; Quéré, D.; Clanet, C. Water Spring: A Model for Bouncing Drops. Europhys. Lett. 2003, 62, 237-243.

(41) Truong, V. K.; Geeganagamage, N. M.; Baulin, V. A.; Vongsvivut, J.; Tobin, M. J.; Luque, P.; Crawford, R. J.; Ivanova, E. P. The Susceptibility of Staphylococcus aureus CIP 65.8 and Pseudomonas aeruginosa ATCC 9721 Cells to the Bactericidal Action of Nanostructured Calopteryx haemorrhoidalis Damselfly Wing Surfaces. Appl. Microbiol. Biotechnol. 2017, 101, 4683-4690.

(42) Jongerius, S. R.; Lentink, D. Structural Analysis of a Dragonfly Wing. Exp. Mech. 2010, 50, 1323-1334.

(43) Wootton, R. J.; Herbert, R. C.; Young, P. G.; Evans, K. E. Approaches to the Structural Modelling of Insect Wings. Philos. Trans. R. Soc., B 2003, 358, 1577-1587.

(44) Richard, D.; Clanet, C.; Quéré, D. Surface Phenomena: Contact Time of a Bouncing Drop. Nature 2002, 417, 811.

(45) Chen, L.; Xiao, Z.; Chan, P. C. H.; Lee, Y.-K.; Li, Z. A Comparative Study of Droplet Impact Dynamics on a Dual-Scaled Superhydrophobic Surface and Lotus Leaf. Appl. Surf. Sci. 2011, 257, $8857-8863$.

(46) Outomuro, D.; Dijkstra, K.-D. B.; Johansson, F. Habitat Variation and Wing Coloration Affect Wing Shape Evolution in Dragonflies. J. Evol. Biol. 2013, 26, 1866-1874.

(47) Johansson, F.; Söderquist, M.; Bokma, F. Insect Wing Shape Evolution: Independent Effects of Migratory and Mate Guarding Flight on Dragonfly Wings. Biol. J. Linn. Soc. 2009, 97, 362-372.

(48) Bhadra, C. M.; Werner, M.; Baulin, V. A.; Truong, V. K.; Al Kobaisi, M.; Nguyen, S. H.; Balcytis, A.; Juodkazis, S.; Wang, J. Y.; Mainwaring, D. E.; Crawford, R. J.; Ivanova, E. P. Subtle Variations in Surface Properties of Black Silicon Surfaces Influence the Degree of Bactericidal Efficiency. Nano-Micro Lett. 2018, 10, 36. 